\title{
Tratados y convenios internacionales y sus impactos sobre las semillas y la economía campesinas
}

\author{
International treaties and agreements and their impacts on \\ seeds and peasant economy
}

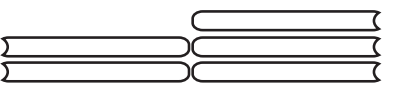

Silvia Rodríguez Cervantes ${ }^{1}$

Recibido: Agosto 2016 Aprobado: marzo 2017

\section{Resumen}

Se analizan los controles legales impuestos a los países por medio de pactos internacionales y sus concomitantes leyes nacionales que afectan las semillas y la economía campesina. Este andamiaje legal constituye uno de los medios para consolidar la agricultura industrial iniciada con los híbridos de la Revolución Verde y en los últimos veinte años con las semillas transgénicas de la Revolución Biotecnológica. Se dan ejemplos de los impactos que estos controles han tenido en los grupos agricultores estadunidenses, primer país que los incorporó en su normativa y algunos casos de otros países. Manejar esta información nos permitirá actuar con conocimiento de causa contra del dominio de las semillas en manos de unas cuantas empresas y a favor del bienestar campesino y la soberanía alimentaria de los países.

Palabras clave: Tratados y leyes, semillas, soberanía alimentaria.

\begin{abstract}
We analyze the legal controls imposed to most countries by different international treaties and its consequent national seed laws. They have a clear effect on the sway over the seeds and on the peasant economy and constitute the channels to strengthen the industrial agriculture that started with the hybrids of the Green Revolution and in the last twenty years with the transgenic seeds product of the Biotechnological Revolution. We give examples of that impact on different US family farmers which were the firsts to endure this type of laws so as some other cases experienced in other countries. To handle this information will allow us to act wittingly against the dominion of few seed companies and in favor of the countries food sovereignty.
\end{abstract}

Keywords: Laws and treaties, seeds, food sovereignty

1 Red de Coordinación en Biodiversidad de Costa Rica. silroce@gmail.com 


\section{Introducción}

"Quien tenga el dominio de los alimentos y previamente el de las semillas, tendrá en sus manos un arma política”, era una expresión que escuchábamos hace ya varias décadas. Empezando el siglo XXI, el expresidente de los Estados Unidos, George Bush, hijo, reafirmó esas ideas para reconocer una nueva e importante función de la autonomía de la producción de alimentos en su país al calificarla como materia de seguridad nacional. Decía:

¿Pueden imaginar un país incapaz de producir suficiente comida para alimentar a su población? Sería una nación sujeta a las presiones internacionales. Sería una nación en riesgo. De esta manera, cuando hablamos de la agricultura estadunidense, estamos hablando realmente de un tema de seguridad nacional. (Bush, 2001, p. 50)

Siguiendo estas y otras razones, es necesario conocer cómo, por medio de controles tecnológicos, contractuales y legales, nuestros países van perdiendo el dominio sobre sus semillas, base de la seguridad nacional que el presidente Bush invocaba para el suyo (Rodríguez Cervantes, 2011).

En este artículo solo analizaré algunos de los controles legales exigidos en pactos internacionales (ya sean tratados, convenios o acuerdos). Estos tienen cláusulas específicas que regulan el uso libre y ancestral de las semillas. Como consecuencia se va consolidando la agricultura industrial y su forma de producción iniciada y expandida con los híbridos de la Revolución Verde, y en los últimos veinte años con los transgénicos de la Revolución Biotecnológica.

En un primer punto, haré un breve repaso cronológico del surgimiento de las leyes y pactos relacionados con el control de las semillas y su interacción. En segundo lugar, me referiré a las repercusiones que todo este andamiaje legal tiene sobre los sistemas de semillas campesinas. Finalmente daré algunas conclusiones

\section{Los pactos internacionales y las leyes de semillas: Puntos de apoyo del sistema de agricultura industrial}

\section{El contexto}

Estados Unidos fue el primer país, que en 1932 otorgó propiedad intelectual (PI) a variedades de plantas de reproducción asexual. Sin embargo, la gran mayoría de los países no siguieron su ejemplo. En Costa Rica, por ejemplo, la posibilidad de otorgar PI a cualquier ser vivo estaba específicamente 
prohibida en la ley respectiva. Con el tiempo, las cosas fueron variando en materia de producción de alimentos.

Primero empezaron los cambios en la esfera tecnológica con la introducción y expansión de las semillas híbridas en la década de los años sesenta. Unos años antes, en 1943, la Fundación Rockefeller había establecido cerca de la ciudad de México un centro de investigación dedicado a la producción de variedades de plantas, conocido posteriormente como Centro Internacional para el Mejoramiento del Maíz y del Trigo. Para 1950, su personal investigador había obtenido las primeras variedades híbridas de trigo de un supuesto mayor rendimiento que, junto con las semillas mejoradas de maíz, sorgo y arroz, fueron la base de la Revolución Verde (Rodríguez Cervantes, 2013, p. 62). Los híbridos pronto fueron ocupando miles de hectáreas en todos los países.

\section{Surgen leyes nacionales y pactos internacionales de semillas}

Como consecuencia de la expansión de las variedades híbridas, las instituciones y empresas interesadas en promover su participación en el mercado semillero mundial empezaron a estimular la aprobación de leyes nacionales de semillas para su propio beneficio. La idea proliferó a inicios de la década de los noventa en distintos países del mundo. En un inicio, estas leyes tenían como énfasis la imposición de normas de certificación (Grain, 2005, pp. 1216). Las semillas que cumplieran los estándares allí exigidos serían las únicas que se podrían comercializar.

Más tarde, las mismas empresas empezaron a demandar la aprobación de un nuevo tipo de leyes, esta vez para controlar la capacidad de reproducción de las semillas. Las semilleras buscaban con esas leyes la eliminación de la costumbre milenaria de los grupos agricultores de guardar parte de su cosecha como simiente para la próxima siembra. Las prácticas de guardar, intercambiar semillas con otros sujetos agricultores y mejorarlas los hace independientes, pues no tienen la necesidad de comprarlas cada año en el mercado formal.

Así, promovidos por seis empresas europeas, se instauraron en 1961 los derechos del sujeto obtentor. Estos constituyen un tipo de derechos de PI otorgados a quienes introduzcan algún cambio en las semillas que les permita calificarlas como diferentes, uniformes y estables. Los derechos de obtentor están establecidos en las diferentes actas de la Unión para la Protección de Obtenciones Vegetales (UPOV). La última de 1991 es la más restrictiva, pues se limitan las excepciones del acta anterior de 1968, entre ellas, el llamado privilegio de guardar semillas concedido a los sectores agricultores, aunque exclusivamente para uso propio. 
Ahora bien, esta Unión tenía que resolver un problema adicional, ya que a fines del siglo veintiuno, casi cuarenta años después de fundada, su adhesión había tenido una limitada aceptación, especialmente de los países del Sur Global. Los interesados en la expansión de UPOV lograron un triunfo parcial al introducir, en 1994, entre los acuerdos de la Organización Mundial del Comercio (OMC, 1994), uno referido a los aspectos de propiedad intelectual relacionados con el comercio (ADPIC). Su artículo 27. 3 b) aprueba un hecho inédito para la gran mayoría de los países, como es obligar a todos los miembros a otorgar PI a los seres vivos, ya sean patentes en el caso de genes modificados por métodos biotecnológicos; o bien, una protección sui generis en el caso de las variedades de plantas. El artículo no es específico y una cantidad de analistas aseguran que países como Estados Unidos hubiesen deseado que se mencionara específicamente a la UPOV como la forma sui generis de proteger la PI de los fitomejoradores u obtentores. Esta falta de claridad originó que, ni siquiera por tratarse de un pacto de la OMC, llegado el año 2000 en que las obligaciones de esta organización entraron en vigor, solo el 30\% de los países había cumplido con las estipulaciones del Art. 27. 3 b) para otorgar derechos de obtentor.

\section{El paso de lo multilateral a lo bilateral}

La evidente lentitud del proceso para cumplir con los acuerdos dentro de las normas de un tratado multilateral como el de la OMC, hizo cambiar de estrategia a países como Estados Unidos que optaron por establecer tratados bilaterales/regionales de libre comercio (TLC), como en el caso del TLC de Estados Unidos con Centro América y República Dominicana (TLC EU-CARD) firmado en el 2003, se podían imponer de manera menos compleja, la adhesión a nueve convenios de PI, entre ellos UPOV-91, entre otros términos.

Como resultado de estos tratados y de otras presiones internacionales, podemos notar el cambio en la membrecía de UPOV. Después de casi cuarenta años de establecida esta Unión, es decir, entre 1962 y 2000 solo había 34 países miembro; en cambio, tan solo 14 años después, de 2001 a 2015, se han sumado otros 40, con un total de 74 .

\section{Acuerdos plurilaterales}

En los últimos años, han empezado a ponerse en boga otros tratados comerciales, ahora plurilaterales, entre ellos el Acuerdo Transpacífico (Trew, Stuart, 2012) que elimina todas las limitaciones para exigir el patentado de plantas y animales y, además, aquí sí se señala específicamente la obligación de ratificar 
el acta de UPOV-91 para otorgar PI de variedades de plantas. Aunque el ATP está considerado plurilateral, solamente firmado por doce países de la cuenca del Pacífico, sus acuerdos marcarán la pauta para incrementar las exigencias de otros pactos.

\section{El Tratado de Recursos Fitogenéticos para la Agricultura y la Alimentación (Tirfaa)}

Es importante mencionar este tratado que tuvo sus orígenes en los primeros años de la década de los ochenta. Después de años de discusión, su desenlace no podría ser más frustrante. En 1981 se había acordado el Compromiso Internacional de Recursos Fitogenéticos que declaraba que el intercambio de todo tipo de semillas fuese libre e irrestricto, tanto de semillas campesinas como de las así llamadas semillas de élite o semillas mejoradas. Este compromiso no era vinculante y, aún así, como era de esperarse, provocó la reacción airada de países y empresas con interés en el dominio del mercado de semillas. Por fin, en 1994 se adoptó el Tirfaa, que es un acuerdo vinculante; pero, en donde, con solo una sola frase, se arruina la posibilidad de defensa de las semillas, al señalar que ninguna de estas será patentada "en la forma recibida" (Tratado de Recursos Fitogenéticos para la Agricultura y la Alimentación [Tirfaa], 2009). Esto quiere decir que automáticamente aquellas con alguna modificación formal, sí podrían obtener PI.

Como disminuida reciprocidad de esa enorme concesión para las empresas semilleras, se concedieron en el Tirfaa (2009) ciertos derechos a los grupos agricultores. Así el inciso 9.3. indica:

Nada de lo que se dice en este Artículo se interpretará en el sentido de limitar cualquier derecho que tengan los agricultores a conservar, utilizar, intercambiar y vender material de siembra o propagación conservado en las fincas, con arreglo a la legislación nacional y según proceda (negrita añadida).

Es claro, entonces, que mientras los derechos de obtentor y de patentes se robustecen cada vez más, los derechos de los agricultores nacieron débiles y crecen peor. Su establecimiento queda a la disposición de lo que cada país defina y, hasta hoy, no conocemos ninguna iniciativa nacional para su implementación.

En resumen, el término genérico de "leyes de semillas" abarca, entre otras, las leyes de certificación, que controlan la comercialización en el llamado mercado formal; y las leyes de PI que, en el caso de las variedades de plantas se 
otorgan principalmente en el Convenio de la UPOV, y que controlan la capacidad de reproducción de las semillas. Hay países en que estos dos tipos de leyes se aprueban de manera independiente, hay otros en los cuales, en una misma legislación se integran ambas exigencias. En Costa Rica, las leyes se han propuesto separadamente.

\section{El andamiaje legal: Uno de los medios de control para erosio- nar el sistema de vida campesino}

El editor de la publicación CropChoice, Robert Schubert (2004), opinaba que "las patentes son la piedra de toque de la revolución biotecnológica. Sin ellas no habría ganancias o control. Durante años Monsanto.... ha utilizado las patentes de sus variedades de semillas genéticamente modificadas, como la base legal para llevar a juicio a agricultores".

Unos años después, en 2009, Oliver De Shutter, relator especial de la ONU sobre el derecho a la alimentación, en una conferencia de prensa previa a la presentación de su informe anual a la Asamblea General de ese organismo, propuso: "modificar las leyes que protegen a la PI para que no se conviertan en un impedimento para el desarrollo de un sector agrícola que proporcione seguridad alimentaria a los más pobres del planeta" (EFE, 2009).

De forma mucho más amplia, pero consecuente con el pensamiento anterior, Cohen (2013) demuestran cómo algunas empresas se han valido de las políticas de protección de la PI para controlar el uso de las semillas agrícolas. Derivados en gran medida de estas, se dan cambios muy fuertes en el sistema de trabajo de los sectores agricultores familiares de ese país y otros países, así como en la investigación.

En vista de que Estados Unidos es el país en donde primero se estableció este tipo de leyes y el seguimiento que se les ha dado en estudios como el arriba mencionado ha sido bien documentado, utilizaré sus ejemplos como base para evaluar el impacto de la PI en el sistema de agricultura campesina, añadiendo otros artículos y declaraciones que los confirman o matizan.

1. Control corporativo de la industria semillera. En 2013 tres empresas, Monsanto, Dupont y Syngenta dominaban el 53\% del mercado global de semillas (Grupo ETC, 2013). Como elemento de comparación para visualizar la rapidez con que ha crecido este fenómeno, hace 36 años, en 1977, existían en el mundo 7,000 empresas semilleras y ninguna controlaba más del 0.05\% del mercado (Ribeiro, 2008). Este control no hubiera podido establecerse sin 
la PI de las semillas. El candado impuesto por ese medio a la capacidad de reproducción de las semillas ha cambiado sustancialmente la tradición histórica del trabajo de los grupos agricultores, quienes ahora tienen que comprar las semillas cada vez que las siembran, una vez que se encuentren bajo el régimen de UPOV o de patentes.

2. Aumento en los precios de las semillas. El reporte consultado indica que, en Estados Unidos, los precios de las semillas han aumentado dramáticamente dado su control monopólico. En el caso de las variedades genéticamente modificadas bajo patentes: El algodón ha subido en 516\% desde 1995; la soya en 325\% y el maíz 259\% en el mismo período (Cohen, 2013).

3. Aumento en otros costos de producción. Las semillas no son el único factor que interviene en este incremento. Las variedades "modernas" demandan el uso de pesticidas, herbicidas y abonos monopolizados por las mismas empresas semilleras, así como buena tierra y suficiente agua. Muchos grupos agricultores han salido de esta actividad al no poder asumir estos costos

4. La innovación de distinto tipo se reduce. El reporte de Cohen (2013) señala que los economistas del Departamento de Agricultura de Estados Unidos han encontrado que el monopolio de la industria agropecuaria de unas cuantas empresas ha reducido el espectro de la investigación a unas cuantas variedades. Esto se traducirá en una "reducción de opciones ofrecidas en el mercado”. (Fernández y Schimmelpfennig, 2004, p.19).

5. La investigación independiente ha sido estrangulada. Para documentar esta afirmación, en una carta dirigida a la Agencia de Protección Ambiental (EPA) de Estados Unidos por reconocido personal científico universitario, señalaban su preocupación por que las patentes y acuerdos tecnológicos estaban malogrando la investigación (Pollack, 2009).

6. Erosión genética. Las grandes corporaciones que favorecen el monocultivo han diezmado las variedades tradicionales. Si esto es apreciable en EEUU, la erosión genética es mucho más notoria y dramática en los países biodiversos, cuna de muchos de los cultivos base de la alimentación mundial. En vísperas de la Conferencia Mundial de Semillas en 2009, el Instituto Internacional para el Medioambiente y el Desarrollo (IIED por sus siglas en inglés), reportó que:

La diversidad de las semillas tradicionales se está reduciendo aceleradamente, lo que significa que valiosos rasgos como la resistencia a las inundaciones y las plagas podrían perderse para siempre... esas variedades están siendo reemplazadas por un rango más reducido de 
semillas 'modernas' que son fuertemente promocionadas por las corporaciones y subvencionadas por los gobiernos. (IIED)

7. Surgimiento de supermalezas. La utilización desmedida de pesticidas como el glifosato ha generado el surgimiento de supermalezas que se tratan de combatir con más plaguicidas sin mucho éxito; pero sí incrementando los costos de producción, la erosión de la tierra y los peligros para la salud.

8. Juicios a personas agricultoras. Solo la empresa Monsanto había establecido en el año 2012, 142 demandas por violación de patentes que involucraron a 410 sujetos agricultores y a 56 empresas agrícolas pequeñas en 27 Estados diferentes de Estados Unidos. Esto genera altos costos y enorme presión para los grupos agricultores acusados por una poderosa empresa como Monsanto (Cohen, 2013).

9. Aspectos sociales. Las empresas agrícolas de mayor capacidad financiera, muchas veces subsidiarias de empresas transnacionales, son las que han tenido la capacidad de comprar y cultivar las semillas híbridas y transgénicas con todas sus exigencias; pero no la mayoría campesina de los países pobres. Así, se sigue incrementando la brecha entre unos sectores y otros. Esto contribuye, día tras día, con el despoblamiento del campo y la proletarización de sus habitantes. El campesinado huyó primero a las ciudades de sus propios países y se estableció en los llamados cinturones de miseria, en búsqueda de nuevos horizontes para poder sobrevivir. Allí su única posibilidad fue convertirse en mano de obra barata local. Posteriormente, millones más han emigrado a los países industrializados, generalmente en forma ilegal en busca de mejores formas de vida.

Es impactante conocer, por ejemplo, del censo agropecuario de Costa Rica el 2014, los datos que señalan que el $80 \%$ del campesinado tiene un promedio de edad de 53 años. Igualmente saber que un gran porcentaje de emigrantes, que salen de Honduras y de El Salvador hacia Estados Unidos, son niños y niñas campesinos que prefieren aventurarse solos en un viaje largo y lleno de peligros, que seguir una vida en el campo sin mayores horizontes.

\section{Conclusiones}

La conciencia de la situación antes descrita ha tenido eco en esferas oficiales. Ya transcribimos el testimonio del relator especial de las Naciones Unidas para la alimentación, Sr. Oliver De Shutter (2011), quien le atribuye a la propiedad intelectual problemas concretos ocasionados a las semillas y de allí a ser una más de las causas del detrimento de la agricultura familiar campesina. 
A estas opiniones agregamos el llamado de la FAO (2010) a detener la erosión genética generada entre otras causas por la sustitución de variedades locales por variedades modernas. Confirma esta organización su compromiso para frenar dicha erosión y preservar la riqueza de los recursos fitogenéticos por medio del $2^{\circ}$ Plan de Acción Mundial.

Sin embargo, pareciera que tales opiniones no generan acciones concretas y que, por el contrario, las empresas transnacionales siguen adelante queriendo ganar más y más terreno para su propio beneficio. Recientemente, el grupo ETC ha denunciado que las empresas semilleras están tomando cartas en el asunto para ver cómo enfrentan la expiración del plazo de varias patentesy como amplían las patentes en genes climáticos (Grupo ETC, 2010). Sabemos igualmente de las aspiraciones de ampliar, en acuerdos plurilaterales como el de la Alianza Trans Pacífico, la materia y los tiempos de la PI a todos sus productos vivos o inertes. De manera que son las organizaciones campesinas, indígenas y ecologistas, apoyadas por personal científico comprometido, las llamadas a hacer denuncias públicas y a luchar por los derechos de los pueblos. Sin esta presencia activa, las empresas transnacionales, en muchos casos apoyadas por los gobiernos, seguirán ampliando su poder en el control de las semillas y de otros recursos naturales.

\section{Referencias}

Bush, George W. (2001). Remarks to the Future Farmers of America. Washington, DC. Recuperado de: http://www.iatp.org/files/Bush_Says_Agriculture_Will_Be_Cornerstone_of_T.htm

Cohen, Sam. (2013). Seed Giants vs. U.S. Farmers. Washington, D.C.: Center for Food Safety.

De Schutter, Olivier. (2011). Agroecology and the Right to Food. Informe presentado en la $16^{a}$ Sesión del Consejo para los Derechos Humanos de las Naciones Unidas [A/HRC/16/49], 8 de marzo, 2011. Citado por Grain. 2014. Recuperado de: https://www.grain.org/bulletin_board/ entries/4219-eco-farming-can-double-food-production-in-10-years

EFE. (26 de octubre, 2009). Relator de la ONU pide modificar las patentes de las semillas comerciales. Recuperado de: www.elpais.cr/articulos. php?id=15126

FAO. (2009). Tratado de Recursos Fitogenéticos para la Agricultura y la Alimentación (Tirfaa). 
FAO. (2010). Crop biodiversity: use it or lose it. FAO launches 2 nd State of the World's Plant Genetic Resources for Food and Agriculture (Report). Recuperado de http://www.fao.org/news/story/en/item/46803/icode/

Fernandez-Cornejo, Jorge y David, E. (February, 2004). Schimmelpfennig, Have Seed Industry Changes Affected Research Effort? USDA Economic Research Service, AmberWaves, 19. Recuperado de http://ageconsearch. umn.edu/bitstream/129915/2/features_seedindustry.pdf

Grain y Vía Campesina. (2015). La criminalización de las semillas campesinas. Resistencias y luchas. Barcelona, España. Recuperado de https://www. grain.org/es/article/entries/5173-la-criminalizacion-de-las-semillascampesinas-resistencias-y-luchas

Grain. (2005). América Latina: La sagrada privatización. Revista Biodiversidad, Sustento y Culturas, 46. Montevideo, Uruguay.

Grupo ETC. (2010). La escalada de patentes sobre "genes climáticos" amenaza la biodiversidad y apunta al acaparamiento de tierra y biomasa. Recuperado de http://www.biodiversidadla.org/Principal/Contenido/Noticias/La_escalada_de_patentes_sobre_genes_climaticos_amenaza_la_ biodiversidad_y_apunta_al_acaparamiento_de_tierra_y_biomasa

Grupo ETC. (2013). Gene Giants Seek “Philanthrogopoly”. Recuperado de http:// www.etcgroup.org/content/Ecomm-gene-giants-seek-philanthrogopoly

Instituto Nacional de Estadística y Censos (2014). Censo Nacional agropecuario de Costa Rica.

International Insitute for Environment and Development (IIED). (2009). Pérdida de variedad semillas complicaría respuesta a cambio clima. Recuperado de http://noticias.terra.com/articulos/act1932937/ Perdida_variedad_semillas_complicaria_respuesta_a_cambio_clima

Muheebwa, Hillary. (2015). New ARIPO Plant Protocol: Conflict of Farmers And Breeders Rights? Recuperado de http://www.ip-watch. org/2015/07/10/new-aripo-plant-protocol-conflict-between-farmersand-breeders-rights

Pollack, Andrew. (February 19, 2009). Crop Scientists Say Biotechnology Seed Companies Are Thwarting Research. The New York Times. Recuperado de http://www.nytimes.com/2009/02/20/business/20crop.html 
Ribeiro, Silvia (enero, 2008). La semilla es imprescindible. Revista Biodiversidad, Sustento y Cultura, 55. Recuperado de http://www.grain.org/ biodiversidad/?type $=42$

Rodríguez Cervantes, Silvia. (2011). Control corporativo de las semillas y sus secuelas. Biocenosis, 24(1-2), 30-44. Revista de Educación Ambiental. Universidad Estatal a Distancia, Costa Rica.

Rodríguez Cervantes, Silvia. (2013). El despojo de la riqueza biológica: De patrimonio de la humanidad a recurso bajo soberanía estatal. Heredia, Costa Rica: Editorial Universidad Nacional. Recuperado de http:// www.euna.una.ac.cr/index.php/99-categorias/lineas-editoriales/ciencias-naturales/120-el-despojo-de-la-riqueza-biologica-de-patrimoniode-la-humanidad-a-recurso-bajo-soberania

Saez, Catherine. (2013). Report On Seed Giants' Initiatives To Preserve Monopoly On Global Food Intellectual Property Watch. Recuperado de http:// www.ip-watch.org/2013/03/08/report-on-antitrust-concerns-seedcompanies-working-to-extend-iprs-to-control-global-food

Schubert, Robert. (1 July, 2004). Monsanto's '435 patent: Now you see it, now you don't. Recuperado de: www.CropChoice.com.

Trew, Stuart. (2012) Few fans of U.S. intellectual property proposals in Trans-Pacific Partnership. September 7. Recuperado de: http://rabble.ca/blogs/bloggers/council-canadians/2012/09/ few-fans-us-intellectual-property-proposals-trans-pacific-p 